\title{
What is the Delaware SEOW?
}

Sharon Merriman-Nai, MC

Senior Consultant, Center for Drug and Health Studies at the University of Delaware

The State Epidemiological Outcomes Workgroup, better known as the SEOW, was established 15 years ago as part of Delaware's first Strategic Prevention Framework (SPF) grant from the U.S. Substance Abuse and Mental Health Services Administration (SAMHSA). SEOWs were funded to promote the use of data to inform prevention efforts at state and local levels. Because of its commitment to guiding prevention and treatment with data, the Delaware Division of Substance Abuse and Mental Health (DSAMH), Department of Health and Social Services has continued to sponsor the SEOW since its beginning. The work group is facilitated by the Center for Drug and Health Studies at the University of Delaware.

The mission of the SEOW is to bring data regarding behavioral health to the forefront of prevention and treatment initiatives. Specifically, the SEOW facilitators convene a network of stakeholders - representatives of state agencies, nonprofits, community organizations, coalitions, task forces, and other entities - to identify data needs, to share data sources and resources, and to inform the development of data products to meet those needs. Based on this input, the facilitator team develops a wide range of materials including heat maps (featured in this issue), infographics, gap reports and an annual epidemiological profile, webinars, and other products to highlight behavioral health trends, risk and protective factors, and groups who may be at disproportionate risk for adversities. The team also provides customized technical assistance to help people use data to support grant application submissions, needs assessment, program planning, evaluation, research, and public awareness and outreach.

Collaboration is critical to the success of the SEOW. There are currently over 100 network members representing approximately 50 Delaware-based organizations. Many provide access to data sources and use their platforms to help "push out" data to support state and local efforts. They also provide recommendations for making data easy to understand and use so that policy makers, practitioners, advocates, and others can translate it into action to foster strong and healthy communities. The SEOW benefits from rigorous, cross-sector engagement. We are grateful to collaborate with our committed partners, including the Delaware Academy of Medicine/Delaware Public Health Association, and to share this information with readers of the Delaware Journal of Public Health. As Roberta Gealt, the former lead facilitator of the SEOW often said, "If you are not using our data, we are not doing our job."

To learn more about the SEOW or to view data resources, please visit: https://www.cdhs.udel.edu/seow/what-is-seow.

Correspondence

Sharon Merriman-Nai, MC, Senior Consultant, Center for Drug and Health Studies at the University of Delaware, smnai@udel.edu

Copyright (c) 2021 Delaware Academy of Medicine / Delaware Public Health Association.

This is an Open Access article distributed under the terms of the Creative Commons Attribution Non-Commercial License (https://creativecommons.org/licenses/by-nc-nd/4.0/) which permits unrestricted non-commercial use, distribution, and reproduction in any medium, provided the original work is properly cited. 